\title{
Effect of thermal annealing on structural and optical properties of In doped Ge-Se-Te chalcogenide thin films
}

\author{
PraVin Kumar Singh ${ }^{1}$, S.K. TRIPATHI ${ }^{2}$, D.K. DWIVEdi ${ }^{1, *}$ \\ ${ }^{1}$ Amorphous Semiconductor Research Lab, Department of Applied Science, Madan Mohan Malaviya University of \\ Technology, Gorakhpur 273010, India \\ ${ }^{2}$ Department of Physics, Punjab University, Chandigarh, India
}

\begin{abstract}
Thin films of $\mathrm{Ge}_{10-\mathrm{x}} \mathrm{Se}_{60} \mathrm{Te}_{30} \mathrm{In}_{\mathrm{x}}(\mathrm{x}=0,2,4$ and 6) were developed by thermal evaporation technique. The annealing effect on the structural properties of $\mathrm{Ge}_{10-\mathrm{x}} \mathrm{Se}_{60} \mathrm{Te}_{30} \mathrm{In}_{\mathrm{x}}(\mathrm{x}=0,2,4$ and 6) films has been studied by X-ray diffraction (XRD). The XRD results indicate amorphous nature of the as-prepared films whereas crystalline phases in annealed films were identified. Structural parameters such as average crystallite size, strain, and dislocation were determined for different annealing temperatures. Effect of annealing on optical constants of prepared films has been explored using UV-Vis spectrophotometer in the wavelength range of $400 \mathrm{~nm}$ to $1000 \mathrm{~nm}$. Various optical constants were determined depending on annealing temperature. It has been noticed that the film transparency and optical bandgap $\mathrm{E}_{\mathrm{g}}$ have been reduced whereas the absorption coefficient $\alpha$ and extinction coefficient $\mathrm{k}$ increased with increasing annealing temperature. It was found that the prepared samples obey the allowed direct transition. The reduction in optical bandgap with annealing temperature has been described by Mott and Davis model. Due to annealing dependence of the optical parameters, the investigated material could be utilized for phase change memory devices.
\end{abstract}

Keywords: chalcogenide glasses; phase transformation; thin films; DSC; optical band gap

\section{Introduction}

Chalcogenide glasses are inorganic amorphous semiconductors having at least one of the chalcogens except oxygen. Usually, more electropositive elements from group 13 to group 15 of the periodic table are used to form glassy matrix. Chalcogenide glasses possess unique properties in comparison with oxide glasses and also the techniques used for their preparation are entirely different [1-4]. Typical properties by which chalcogenide glasses differ from oxide glasses are namely their wide optical transparency in the infrared range of the electromagnetic spectrum and significantly higher refractive index values. Chalcogenide glasses have structural flexibility (low coordination of chalcogens) and high-lying lone-pair $\mathrm{p}$ state in their valence bands which often results in structural, optical, electrical changes when exposed to suitable radiation or annealing $[5,6]$. Chalcogenide glasses

*E-mail: todkdwivedi@gmail.com of ternary $\mathrm{Ge}-\mathrm{Se}-\mathrm{Te}$ system have received great attention due to scientific as well as technological applications [7-10]. The system can be made quaternary by doping In element into this ternary alloy.

Amorphous selenium has been found to have enormous applications in xerography and in various industrial fields like solar technology, photoelements, lubricants and pharmaceuticals as well as metal coating $[11,12]$. It also shows a remarkable feature of reversible phase transformation (amorphous-crystalline transformation). This feature is very useful for optical memory devices. But pure selenium has some drawbacks because of its low sensitivity, shorter life time, poor thermal stability and larger aging effect. To overcome these drawbacks some additive materials are used with selenium which gives smaller aging effect, high crystallization temperature, greater hardness, higher sensitivity and high conductivity $[6,8,13-16]$.

When $\mathrm{Te}$ is added to $\mathrm{Se}$, Te atom behaves as bond modifier and helps in strengthening 
the average bond by cross linking the Se-chain structure which is ultimately responsible for the increase in corrosion resistance, resistivity and glass transition temperature [17-19]. The incorporation of the third element, i.e. Ge is known to contribute to long term room temperature stability [20, 21]. In the recent years, it has been reported that metallic additives have an appreciable effect on physical properties of glassy network [22, 23].

In the present work, In has been chosen as a chemical modifier in Ge-Se-Te ternary system which may further broaden the glass forming area and also can create compositional and configurational disorder in the system with respect to ternary alloys. It should provide better understanding of optical properties of Ge-Se-Te-In system [24-26].

From the literature survey, it is evident that appreciable attention has been paid to Se based binary and ternary glasses [7-11], whereas very less effort has been made to the study of synthesis and investigation of Se-based quaternary glasses which may further extend the utility of these glasses. The obtained selenium based chalcogenide glasses have various applications as efficient solar cell materials, holographic recording systems, memory switching devices and infrared sensors [27-29].

This paper reports thermo-induced structural changes and consequent changes in optical constants of Ge-Se-Te-In multicomponent chalcogenide thin films. Due to annealing dependence of the optical constants, the investigated material could be used for optical data storage.

\section{Experimental}

In the present work, $\mathrm{Ge}_{10-\mathrm{x}} \mathrm{Se}_{60} \mathrm{Te}_{30} \operatorname{In}_{\mathrm{x}}(\mathrm{x}=0$, 2,4 and 6) glasses were synthesized by the wellknown melt quench technique. Simple steps for material preparation include crushing, weighing, sealing, heating then rapid cooling. Upon cooling a liquid below its melting temperature, it will either crystallize or form a glass. High purity $(99.999 \%)$ $\mathrm{Ge}, \mathrm{Se}, \mathrm{Te}$ and In elements were weighed in accordance to their atomic proportion with the help of an electronic balance (LIBROR, AGE-120) having least count of $0.0001 \mathrm{~g}$. The prepared samples were placed in quartz ampoules (length $=5 \mathrm{~cm}$, internal diameter $=8 \mathrm{~mm}$ ) and compressed in the tube of a high vacuum unit to remove the air from the sample. High vacuum $\left(2.66 \times 10^{-3} \mathrm{~Pa}\right)$ was created by using a diffusion pump. Evacuated quartz ampoules (containing the samples) were sealed by LPG-oxygen flame. The sealed ampoules were hooked up in ceramics with the help of nichrome wire and placed in a muffle furnace. The ampoules were heated to $\sim 800{ }^{\circ} \mathrm{C}$ and maintained at that temperature for 12 hours, so as the compound mixture could melt. Furnace temperature was raised steadily at a rate of $4{ }^{\circ} \mathrm{C} / \mathrm{min}$ to $5{ }^{\circ} \mathrm{C} / \mathrm{min}$ throughout the heating. The ampoules were occasionally rocked with a rotating ceramic rod. This process ensured homogeneous glassy alloys. After 12 hour the ampoule was quickly dipped in ice cooled water. After quenching, prepared sample was taken out by crushing the quartz ampoule.

Thin films of glassy composite of Ge-Se-Te-In were developed by thermal evaporation method in which the substrate was retained at room temperature under $2.66 \times 10^{-4} \mathrm{~Pa}$ base pressure with the help of molybdenum boat. To obtain the metastable equilibrium, the prepared films were placed in the deposition chamber for $24 \mathrm{~h}$. The prepared film thickness, measured with the help of single crystal thickness monitor was $400 \mathrm{~nm}$. X-ray diffractometer (X'Pert Pro, $\mathrm{CuK} \alpha$ radiation $\lambda=1.54 \AA$ ) was used to record the XRD pattern of the prepared thin films. The tube was maintained at $45 \mathrm{kV}$ and $40 \mathrm{~mA}$. To ascertain the crystallization temperature, differential scanning callorimetric (DSC) measurement was performed on the powdered sample of $\mathrm{Ge}-\mathrm{Se}-\mathrm{Te}-\mathrm{In}$ under pure $\mathrm{N}_{2}$ atmosphere using Metter Toledo Star instrument (Model No: DSC 200PC). Thin films of $\mathrm{Ge}_{10-\mathrm{x}} \mathrm{Se}_{60} \mathrm{Te}_{30} \mathrm{In}_{\mathrm{x}}$ were annealed in a specific designed sample holder for $2 \mathrm{~h}$ in the presence of a vacuum of $10^{-2} \mathrm{~Pa}$ at three different temperatures $(373 \mathrm{~K}, 393 \mathrm{~K}$, $413 \mathrm{~K}$ ), which was above the glass transition temperature and below the crystallization temperature of the sample. The normal incidence absorption spectra of $\mathrm{Ge}_{10-\mathrm{x}} \mathrm{Se}_{60} \mathrm{Te}_{30} \mathrm{In}_{\mathrm{x}}(\mathrm{x}=0,2,4$ and 6) thin films have been measured by a double beam UV-Vis computer controlled spectrophotometer (ECIL-hayderabad, India, Model No: 5704ss) in the wavelength range of $400 \mathrm{~nm}$ to $1000 \mathrm{~nm}$. 


\section{Results and discussion}

\subsection{Structural properties}

To find the glass transition and crystallization temperature of $\mathrm{Ge}_{10-\mathrm{x}} \mathrm{Se}_{60} \mathrm{Te}_{30} \operatorname{In}_{\mathrm{x}}(\mathrm{x}=0,2,4$ and $6)$ glasses, DSC measurements were performed at a heating rate of $10 \mathrm{~K} / \mathrm{min}$. In the studied temperature span, two sharp peaks are observed which is shown in Fig. 1. The first peak is endothermic, showing the glass transition temperature $\mathrm{T}_{\mathrm{g}}$, whereas the other peak is an exothermic peak representing the crystallization temperature $\mathrm{T}_{\mathrm{c}}$. Glassy nature of prepared $\mathrm{Ge}_{10-\mathrm{x}} \mathrm{Se}_{60} \mathrm{Te}_{30} \mathrm{In}_{\mathrm{x}}(\mathrm{x}=0,2,4$ and 6) compositions was confirmed by the occurrence of glass transition in DSC results. Table 1 shows the values of glass transition $T_{g}$, onset crystallization $T_{x}$ and crystallization temperature $T_{c}$ at a heating rate $10{ }^{\circ} \mathrm{C} / \mathrm{min}$.

Table 1. Glass transition $T_{g}$, crystallization temperature $T_{c}$ and onset crystallization $T_{x}$ for glassy $\mathrm{Ge}_{10-\mathrm{x}} \mathrm{Se}_{60} \operatorname{Te}_{30} \operatorname{In}_{\mathrm{x}}(\mathrm{x}=0,2,4$ and 6) alloys.

\begin{tabular}{lcccc}
\hline \multicolumn{1}{c}{ Compositions } & $\begin{array}{c}\mathrm{T}_{\mathrm{g}} \\
{\left[{ }^{\circ} \mathrm{C}\right]}\end{array}$ & $\begin{array}{c}\mathrm{T}_{\mathrm{c}} \\
{\left[{ }^{\circ} \mathrm{C}\right]}\end{array}$ & $\begin{array}{c}\mathrm{T}_{\mathrm{x}} \\
{\left[{ }^{\circ} \mathrm{C}\right]}\end{array}$ & $\begin{array}{c}\Delta \mathrm{T}=\mathrm{T}_{\mathrm{x}}-\mathrm{T}_{\mathrm{g}} \\
{\left[{ }^{\circ} \mathrm{C}\right]}\end{array}$ \\
\hline \hline $\mathrm{Ge}_{10} \mathrm{Se}_{60} \mathrm{Te}_{30}$ & 93.49 & 201.24 & 164.90 & 71.41 \\
$\mathrm{Ge}_{8} \mathrm{Se}_{60} \mathrm{Te}_{30} \mathrm{In}_{2}$ & 88.48 & 176.91 & 146.76 & 58.28 \\
$\mathrm{Ge}_{6} \mathrm{Se}_{60} \mathrm{Te}_{30} \mathrm{In}_{4}$ & 86.50 & 172.47 & 137.91 & 51.41 \\
$\mathrm{Ge}_{4} \mathrm{Se}_{60} \mathrm{Te}_{30} \mathrm{In}_{6}$ & 84.14 & 159.07 & 129.07 & 44.93 \\
\hline
\end{tabular}

As a representative case, the $\mathrm{X}$-ray diffraction (XRD) graphs of $\mathrm{Ge}_{6} \mathrm{Se}_{60} \mathrm{Te}_{30} \mathrm{In}_{4}$ thin film in asprepared and annealed state at different temperatures are depicted in Fig. 2. From the XRD pattern of the as prepared sample it is clear that there isn't any sharp peak, which confirms the typical amorphous nature of the prepared composition. This means that no nuclei have been formed in the sample throughout its preparation.

This result is very important for understanding the mechanism of crystallization. In order to produce crystalline phase in the $\mathrm{Ge}_{10-\mathrm{x}} \mathrm{Se}_{60} \mathrm{Te}_{30} \mathrm{In}_{\mathrm{x}}$ $(\mathrm{x}=0,2,4$ and 6) thin films, the prepared samples were annealed for $2 \mathrm{~h}$ in a vacuum furnace $\left(1.33 \times 10^{-1} \mathrm{~Pa}\right)$ at three different temperatures of $373 \mathrm{~K}, 393 \mathrm{~K}, 413 \mathrm{~K}$. The XRD patterns of annealed films indicate the existence of crystalline peaks. This shows that thermal annealing induces the amorphous to crystalline phase transformation. This property is useful for optical data storage devices [26].

$\mathrm{Ge}_{10-\mathrm{x}} \mathrm{Se}_{60} \mathrm{Te}_{30} \mathrm{In}_{x}(\mathrm{x}=0,2,4$ and 6) thin films annealed at $373 \mathrm{~K}, 393 \mathrm{~K}, 413 \mathrm{~K}$ for $2 \mathrm{~h}$ show the existence of crystalline peaks. The appearance of the crystalline peaks is due to $\mathrm{Te}, \mathrm{GeSe}$ and $\mathrm{GeSe}_{2}$ phases identified by X'Pert high score plus software.

The well-known Scherer formula [30] was used to calculate the average crystallite size D:

$$
D=\frac{k \lambda}{\beta \cos \theta}
$$

where $\lambda$ is the wavelength of X-ray in $\AA, \beta$ represents full width at half maximum (FWHM) in radian and $\theta$ shows the diffraction angle in degree. The Scherer constant k denotes grain shape factor, and has a value of 0.94 . The structural parameters, dislocation density $\delta$ and strain $\mu$ were calculated using crystallite size. The dislocation density $\delta$ is obtained by the following relation [31]:

$$
\delta=\frac{n}{D^{2}}
$$

where $\mathrm{n}$ denotes a factor whose unity value gives minimum dislocation density. The strain value $\mu$ is obtained from the following relation [19]:

$$
\mu=\left(\frac{\lambda}{D \cos \theta}-\beta\right) \frac{1}{\tan \theta}
$$

Table 2 shows the calculated values of $\mathrm{D}, \delta$, and $\mu$. It is noticed that the average crystallite size increases as a function of annealing temperature. The average crystallite size increases from $10.09 \mathrm{~nm}$ to $12.62 \mathrm{~nm}$, when the annealing temperature rises from $373 \mathrm{~K}$ to $413 \mathrm{~K}$. Furthermore, it can be noticed that the diffraction intensity of the sample annealed at $413 \mathrm{~K}$ is much stronger than that of annealed at $273 \mathrm{~K}$. This is because of an increase in surface diffusion of adsorbed species with annealing temperature.

\subsection{Optical properties}

Optical properties of a material are normally employed to determine its optical constants such 


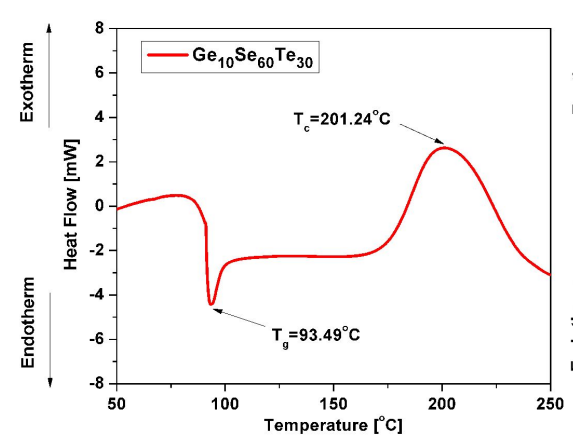

(a)

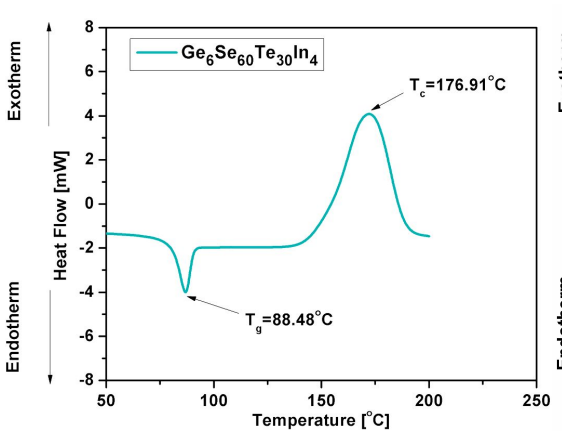

(c)

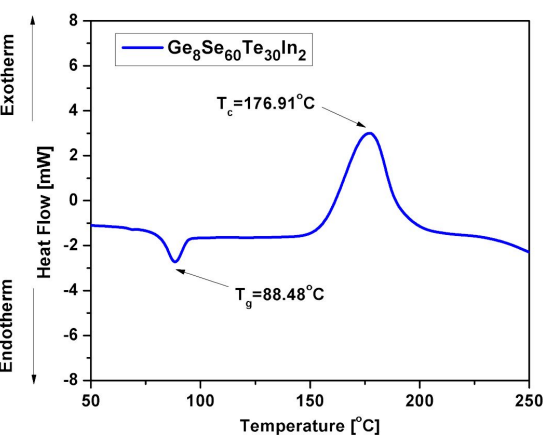

(b)

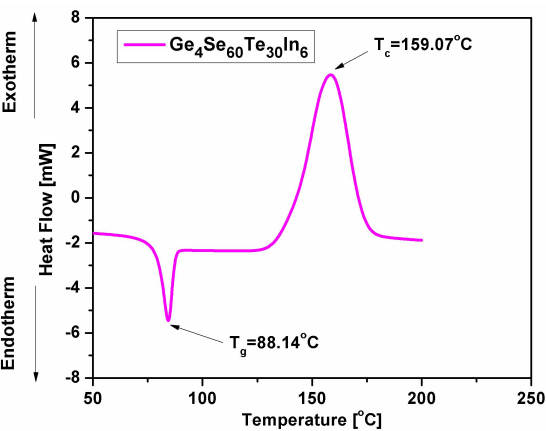

(d)

Fig. 1. DSC thermograms for glassy $\mathrm{Ge}_{10-\mathrm{x}} \mathrm{Se}_{60} \mathrm{Te}_{30} \mathrm{In}_{\mathrm{x}}(\mathrm{x}=0,2,4$ and 6$)$ alloys at a heating rate of $10{ }^{\circ} \mathrm{C} / \mathrm{min}$.

Table 2. Calculated values of crystallite size $\mathrm{D}$, dislocation density $\delta$ and lattice strain $\mu$ for annealed $\mathrm{Ge}_{6} \mathrm{Se}_{60} \mathrm{Te}_{30} \mathrm{In}_{4}$ thin films.

\begin{tabular}{lclllll}
\hline $\begin{array}{l}\text { Sample } \\
\mathrm{Ge}_{6} \mathrm{Se}_{60} \mathrm{Te}_{30} \mathrm{In}_{4}\end{array}$ & $2 \theta\left[^{\circ}\right]$ & $\begin{array}{l}\text { FWHM } \\
(\beta)\end{array}$ & $\begin{array}{l}\text { Crystallite } \\
\text { size D [nm] }\end{array}$ & $\begin{array}{l}\text { Average } \\
\text { crystallite } \\
\text { size D [nm] }\end{array}$ & $\begin{array}{l}\text { Dislocation } \\
\text { density } \delta, \\
10^{15}\left[\mathrm{~m}^{-2}\right]\end{array}$ & $\begin{array}{l}\text { Lattice } \\
\text { strain } \mu\end{array}$ \\
\hline \hline Thermal & 23.22 & 0.80 & 10.59 & & 8.92 & 0.014 \\
annealing at & 28.61 & 0.82 & 10.45 & 10.09 & 9.16 & 0.017 \\
$273 \mathrm{~K}$ & 40.90 & 0.96 & 9.23 & & 11.74 & 0.011 \\
& 23.22 & 0.76 & 11.15 & & 8.04 & 0.016 \\
Thermal & 28.65 & 0.80 & 10.71 & & 0.72 & 0.013 \\
annealing at & 40.93 & 0.88 & 10.07 & 10.50 & 9.86 & 0.010 \\
$293 \mathrm{~K}$ & 45.13 & 0.89 & 10.10 & & 9.80 & 0.009 \\
& 23.23 & 0.55 & 15.58 & & 4.12 & 0.009 \\
Thermal & 28.71 & 0.70 & 12.11 & & 6.82 & 0.014 \\
annealing at & 40.96 & 0.87 & 10.18 & 11.47 & 9.65 & 0.010 \\
413 K & 45.13 & 0.89 & 10.10 & & 9.80 & 0.009 \\
& 51.24 & 0.98 & 9.39 & & 11.34 & 0.008 \\
\hline
\end{tabular}

as absorption coefficient $\alpha$, extinction coefficient in semiconducting thin films. The absorption $\mathrm{k}$, optical band gap $\mathrm{E}_{\mathrm{g}}$, Urbach energy $\mathrm{E}_{\mathrm{e}}$, etc. coefficient $\alpha$ is acquired from the absorbance versus wavelength data using the equation [32-34]:

\subsubsection{Absorption properties}

The absorption coefficient $\alpha$ is a vital parameter for determining optical constants

$$
\alpha=\frac{O D}{t}
$$




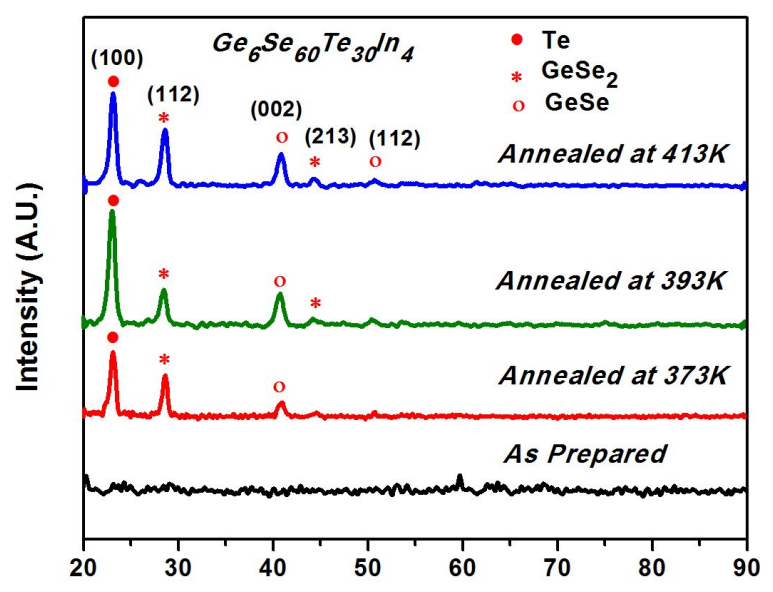

Fig. 2. X-ray diffraction pattern of as-prepared and annealed $\mathrm{Ge}_{6} \mathrm{Se}_{60} \mathrm{Te}_{30} \mathrm{In}_{4}$ thin films.

where OD denotes optical density and t denotes layer thickness. Absorption coefficient $\alpha$ versus incident photon energy $\mathrm{h} v$ for as-prepared and annealed films of $\mathrm{Ge}_{6} \mathrm{Se}_{60} \mathrm{Te}_{30} \mathrm{In}_{4}$ are depicted in Fig. 3. It is found that absorption coefficient increases with photon energy. The same results were found in other thin films $\mathrm{Ge}_{10-\mathrm{x}} \mathrm{Se}_{60} \mathrm{Te}_{30} \mathrm{In}_{\mathrm{x}}$ ( $\mathrm{x}=0,2$ and 6) (data not shown here). The values of absorption coefficient at the wavelength of $620 \mathrm{~nm}$ are displayed in Table 3. The results are in good agreement with results reported in the literature [7-9, 26].

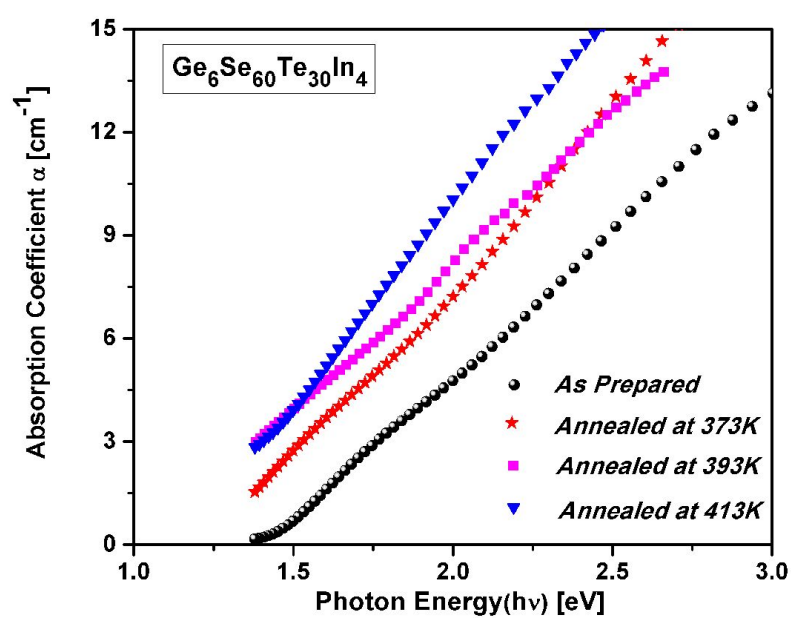

Fig. 3. Variation of absorption coefficient $\alpha$ as a function of photon energy $h v$ in as-prepared and annealed $\mathrm{Ge}_{6} \mathrm{Se}_{60} \mathrm{Te}_{30} \mathrm{In}_{4}$ thin films.
Absorption process occurs when a photon stimulates an electron to a higher energy state from a lower energy state corresponding to an absorption edge. In chalcogenide glasses, a typical absorption edge can be ascribed to one of the three processes; residual below gap absorption, Urbach tail and interband absorption. Chalcogenide glasses have been found to exhibit highly reproducible optical edges which are relatively insensitive to preparation conditions and only the observable absorption [35] with a gap under equilibrium conditions accounts for the first process [32]. Similar trend has also been observed in other types of chalcogenides [7-9, 25, 26, 36]. In Fig. 3, there is a notable change in the gradient of absorption coefficient graph for as-prepared and annealed thin films showing clearly how annealing process influenced the change in material absorption properties. This change has direct influence on changing the optical bandgap as shown in Fig. 4. The general change in absorption coefficient of the material with annealing temperature is mainly a result of the crystal size development and growth.

In most of amorphous semiconductors, fundamental absorption follows the exponential law. Absorption coefficient obeys the well-known Tauc relation [35] above the exponential tails:

$$
(\alpha h v)^{\frac{1}{n}}=A\left(h v-E_{g}\right)
$$

where $v$ is frequency of the incident beam, A is a constant that depends on transition probability, $\mathrm{E}_{\mathrm{g}}$ is optical band-gap and $\mathrm{n}$ is an index which shows type of transition and it can assume values such as $1 / 2,3 / 2,2$ and 3 based on the type of electronic transition causing the absorption $(\mathrm{n}=1 / 2$ shows allowed direct transition, $n=3 / 2$ shows forbidden direct transition, $\mathrm{n}=2$ shows allowed indirect transition, $\mathrm{n}=3$ shows forbidden indirect transition). In the studied $\mathrm{Ge}_{10-\mathrm{x}} \mathrm{Se}_{60} \mathrm{Te}_{30} \operatorname{In}_{\mathrm{x}}(\mathrm{x}=0,2,4$ and 6) thin films, equation 5 fits best the experimental results when $n=1 / 2$. Variations of $(\alpha \mathrm{h} v)^{2}$ versus incident photon energy h $v$ for as-prepared and annealed films of $\mathrm{Ge}_{6} \mathrm{Se}_{60} \mathrm{Te}_{30} \mathrm{In}_{4}$ are presented in Fig. 4.

The value of direct optical bandgap $\mathrm{E}_{\mathrm{g}}$ has been found by extrapolating the linear portion 
Table 3. Absorption coefficient $\alpha$, extinction coefficient $\mathrm{k}$ and Urbach energy $\mathrm{E}_{\mathrm{e}}$ for $\mathrm{Ge}_{6} \mathrm{Se}_{60} \mathrm{Te}_{30} \mathrm{In}_{4}$ glassy alloys.

\begin{tabular}{lllll}
\hline Samples & \multicolumn{4}{c}{ Optical bad gap E $\mathrm{g}_{\mathrm{g}}[\mathrm{eV}]$} \\
\hline \hline & As-prepared & $\begin{array}{l}\text { Annealed at } \\
373 \mathrm{~K}\end{array}$ & Annealed at & Annealed \\
& & 1.68 & 1.62 & at $413 \mathrm{~K}$ \\
$\mathrm{Ge}_{10} \mathrm{Se}_{60} \mathrm{Te}_{30}$ & 1.80 & 1.72 & 1.65 & 1.60 \\
$\mathrm{Ge}_{8} \mathrm{Se}_{60} \mathrm{Te}_{30} \mathrm{In}_{2}$ & 1.87 & 1.76 & 1.70 & 1.62 \\
$\mathrm{Ge}_{6} \mathrm{Se}_{60} \mathrm{Te}_{30} \mathrm{In}_{4}$ & 1.96 & 1.78 & 1.72 & 1.67 \\
$\mathrm{Ge}_{4} \mathrm{Se}_{60} \mathrm{Te}_{30} \mathrm{In}_{6}$ & 1.99 & &
\end{tabular}

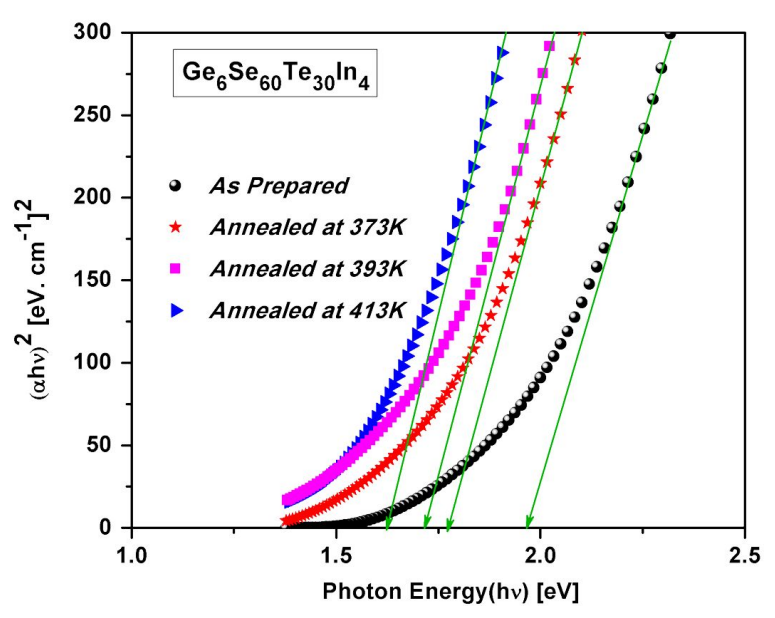

Fig. 4. Variation of $(\alpha \mathrm{h} v)^{2}$ versus photon energy $\mathrm{h} v$ for as-prepared and annealed $\mathrm{Ge}_{6} \mathrm{Se}_{60} \mathrm{Te}_{30} \mathrm{In}_{4}$ thin films

of the Tauc plot to zero, where the factor $(\alpha \mathrm{h} v)^{2} \rightarrow$ 0 , as $\alpha \rightarrow 0$. The obtained values of $\mathrm{E}_{\mathrm{g}}$ for all asprepared and annealed $\mathrm{Ge}_{10-\mathrm{x}} \mathrm{Se}_{60} \mathrm{Te}_{30} \mathrm{In}_{\mathrm{x}}(\mathrm{x}=0$, 2, 4 and 6) thin films are collected in Table 3. From Table 3 it is observed that optical band gap of annealed film of $\mathrm{Ge}_{10-\mathrm{x}} \mathrm{Se}_{60} \mathrm{Te}_{30} \mathrm{In}_{\mathrm{x}}(\mathrm{x}=0,2,4$ and 6) decreases with increasing annealing temperature. Also maximum change in optical bandgap appears for the $\mathrm{Ge}_{4} \mathrm{Se}_{60} \mathrm{Te}_{30} \mathrm{In}_{6}$ thin film.

Thermal annealing effect on the tail width of localized states $\mathrm{E}_{\mathrm{e}}$ (Urbach energy) of the thin films has been studied by heating the films at three temperatures $373 \mathrm{~K}, 393 \mathrm{~K}, 413 \mathrm{~K}$ for $2 \mathrm{~h}$ in a vacuummaintained furnace. Photon absorption occurs between localized tail states and extended band states in the weak absorption region $\left(\alpha<10^{4} \mathrm{~cm}^{-1}\right) . \alpha$ is expressed in exponential form as [37]:

$$
\alpha=\alpha_{0} \exp \left(h v / E_{e}\right)
$$

where $\alpha_{0}$ denotes a constant and $\mathrm{E}_{\mathrm{e}}$ denotes the tail width of localized states (Urbach energy). Urbach energy $E_{\mathrm{e}}$ has been obtained from the reciprocal of the slope of the linear region of the graph of $\ln (\alpha)$ versus photon energy hv. Variations of $\ln (\alpha)$ with photon energy h $v$ of as-prepared and annealed thin films are shown in Fig. 5.

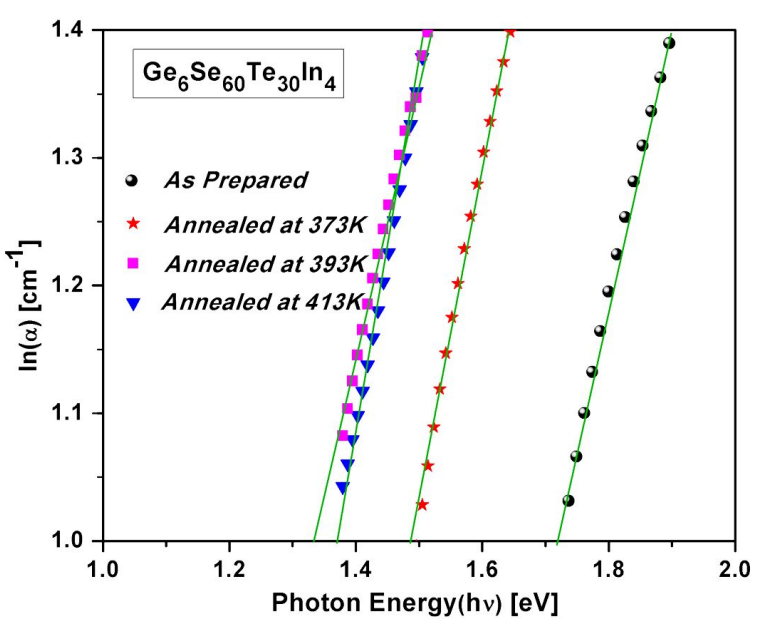

Fig. 5. Variation of $\ln (\alpha)$ versus photon energy $h v$ for as-prepared and annealed $\mathrm{Ge}_{6} \mathrm{Se}_{60} \mathrm{Te}_{30} \mathrm{In}_{4}$ thin films.

From Fig. 5 it is clear that Urbach energy $E_{\mathrm{e}}$ increases with annealing temperature therefore, the width of localized states depends on the thermal annealing. Since Urbach energy $E_{e}$ generally indicates the degree of disorder [38], due to excitationphonon interaction or electron-phonon interaction Urbach energy $E_{\mathrm{e}}$ represents the broadening of the absorption edge. The change of optical band gap $E_{g}$ and Urbach energy $E_{e}$ on annealing temperature are depicted in Fig. 6. It is noticed that optical band 
gap $E_{g}$ decreases while Urbach energy $E_{e}$ increases with increasing annealing temperature.

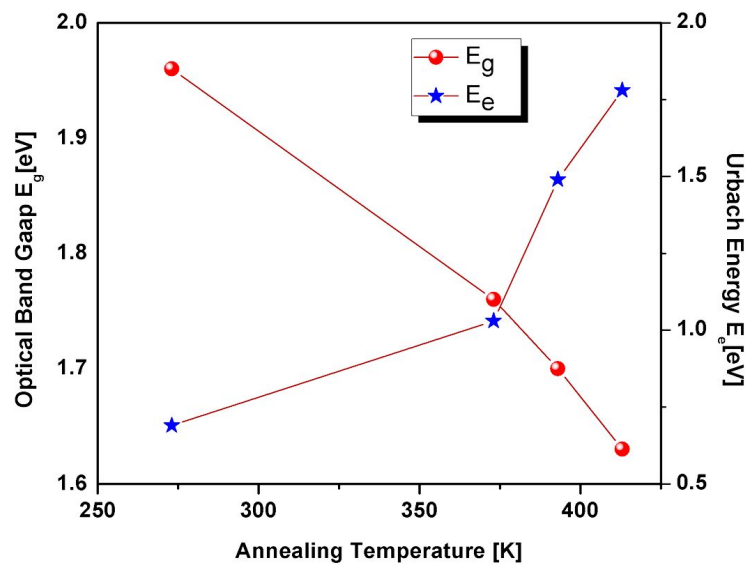

Fig. 6. The dependence of optical band gap $\mathrm{E}_{\mathrm{g}}$ and Urbach energy $E_{e}$ on annealing temperature $K$ in as-prepared and annealed $\mathrm{Ge}_{6} \mathrm{Se}_{60} \mathrm{Te}_{30} \mathrm{In}_{4}$ thin films.

The reduction in the optical band gap $E_{g}$ and increase in the band width of localized states $E_{\mathrm{e}}$ with heat treatment could be explained by presuming the formation of surface dangling bonds during crystallization process [39]. Mott et al. [40] proposed that amorphous solids crystallize under thermal annealing, and that in the crystallization process dangling bonds are created on the surface of the crystallites [41, 42]. It is evident from the XRD results that heat treatment causes an increase in the number of crystallites as well as average crystallite size which eventually results in an increase in the number of surface dangling bonds [7, 40]. These dangling bonds are responsible for generation of some types of defects in highly polycrystalline solids. The amount of dangling bonds in the films increases as a function of annealing temperature which results in the increase of concentration of localized states in the band structure. Thus, the thermal annealing of the prepared thin films leads to an increase in the energy width of localized states thereby reducing the optical energy gap. Our result is in good agreement with the most recently reported results in the literature $[43,44]$.

\subsubsection{Extinction coefficient $k$}

The study of extinction coefficient $\mathrm{k}$ is very significant as it decides the usefulness of the developed composite material for application in photo-electrochemical and photocatalytic applications, photosensors, memory devices, photoelectronics, phase change materials, etc. [26]. The extinction coefficient defines a measure of the fractional loss due to scattering and absorption per unit distance of the propagating medium. It is directly obtained by the equation:

$$
k=\frac{\alpha \lambda}{4 \pi}
$$

where, $\alpha$ denotes absorption coefficient and $\lambda$ indicates photon wavelength. The change of extinction coefficient $\mathrm{k}$ as a function of wavelength $\lambda$ of $\mathrm{Ge}_{6} \mathrm{Se}_{60} \mathrm{Te}_{30} \mathrm{In}_{4}$ thin film is shown in Fig. 7. From Fig. 7 , it is clear that $\mathrm{k}$ increases with increase of annealing temperature. Similar results have also been reported in the literature [7-9, 26, 43, 44]. The increase in extinction coefficient with increase of annealing temperature could be a result of an increase in the crystallites size with annealing temperature [29].

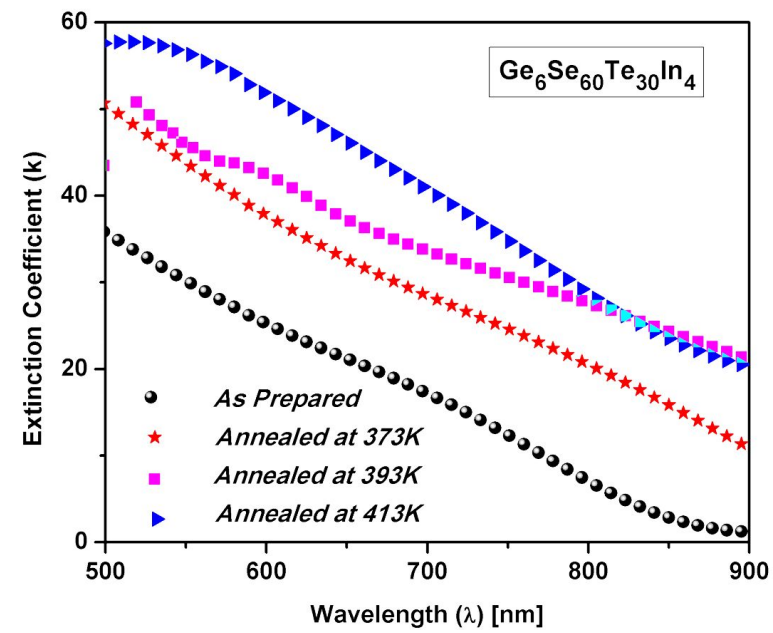

Fig. 7. Variation of extinction coefficient $\mathrm{k}$ with wavelength $\lambda$ in as-prepared and annealed $\mathrm{Ge}_{6} \mathrm{Se}_{60} \mathrm{Te}_{30} \mathrm{In}_{4}$ thin films.

The calculated value of absorption coefficient $\alpha$ and extinction coefficient $\mathrm{k}$ for as-prepared and 
Table 4. Optical band gap $\mathrm{E}_{\mathrm{g}}$ of $\mathrm{Ge}_{6} \mathrm{Se}_{60} \mathrm{Te}_{30} \mathrm{In}_{4}$ thin film at different annealing temperatures.

\begin{tabular}{lccc}
\hline $\begin{array}{l}\text { Sample } \\
\mathrm{Ge}_{6} \mathrm{Se}_{60} \mathrm{Te}_{30} \mathrm{In}_{4}\end{array}$ & $\begin{array}{c}\text { Absorption } \\
\text { coefficient } \\
\alpha \times 10^{4}\left[\mathrm{~cm}^{-1}\right]\end{array}$ & $\begin{array}{c}\text { Extinction } \\
\text { coefficient k }\end{array}$ & $\begin{array}{c}\text { Urbach energy E } \\
{[\mathrm{eV}]}\end{array}$ \\
\hline \hline As-prepared & 4.78 & 23.72 & 0.69 \\
Annealed at 373K & 7.23 & 35.75 & 1.03 \\
Annealed at 393K & 8.23 & 40.65 & 1.49 \\
Annealed at 413K & 10.13 & 49.56 & 1.78 \\
\hline
\end{tabular}

annealed films of a $\mathrm{Ge}_{6} \mathrm{Se}_{60} \mathrm{Te}_{30} \mathrm{In}_{4}$ at $620 \mathrm{~nm}$ have been listed in Table 4 .

Similar results were found for $\alpha$ and $\mathrm{k}$ in $\mathrm{Ge}_{10-\mathrm{x}} \mathrm{Se}_{60} \mathrm{Te}_{30} \mathrm{In}_{\mathrm{x}}(\mathrm{x}=0,2$, and 6) thin films (data not shown here).

\section{Conclusions}

Thin films of multicomponent chalcogenide glasses of $\mathrm{Ge}_{10-\mathrm{x}} \mathrm{Se}_{60} \mathrm{Te}_{30} \mathrm{In}_{\mathrm{x}}(\mathrm{x}=0,2,4$ and 6) were developed on glass substrates by thermal evaporation technique. The XRD studies show that the as-prepared $\mathrm{Ge}_{10-\mathrm{x}} \mathrm{Se}_{60} \mathrm{Te}_{30} \mathrm{In}_{\mathrm{x}}(\mathrm{x}=0,2,4$ and 6) films are amorphous in nature, whereas the annealed films show a phase change. The effect of thermal annealing induces phase transformation (amorphous-crystalline) in the structure of thin films. The average crystallite size has been obtained by the well-known Scherer formula. The average crystallite size increases from $10.08 \mathrm{~nm}$ to $12.64 \mathrm{~nm}$, when the annealing temperature increases from $373 \mathrm{~K}$ to $413 \mathrm{~K}$. It is noticed that absorption coefficient $\alpha$ and extinction coefficient $\mathrm{k}$ are sensitive to annealing temperature (they increase with increasing annealing temperature). The obtained value of optical band gap $E_{g}$ decreases while Urbach energy $E_{u}$ increases by varying annealing temperature from $373 \mathrm{~K}$ to $413 \mathrm{~K}$. This decrease in optical bandgap with annealing temperature was explained with the help of amorphouscrystalline phase transformations model proposed by Mott et al. From the studied compositions of indium doped $\mathrm{Ge}-\mathrm{Se}-\mathrm{Te}$ thin films, it has been noticed that maximum change in optical constants appears for $\mathrm{Ge}_{4} \mathrm{Se}_{60} \mathrm{Te}_{30} \mathrm{In}_{6}$ thin film. Therefore, $\mathrm{Ge}_{4} \mathrm{Se}_{60} \mathrm{Te}_{30} \mathrm{In}_{6}$ is the optimized composition for optical data storage.

\section{Acknowledgements}

Authors are thankful to the UGC-DAE-CSR Indore, India, for providing the facility and financial assistance for DSC and XRD measurements.

\section{References}

[1] Hart S.D., Maskaly G.R., Temelkuran B., Prideaux P.H., Joannopoulos J.D., Fink Y., Science, 296 (2002), 510.

[2] Nicolas H., Laniel J.M., Valle R., VilLENEUVE A., Opt. Lett., 28 (2003), 965.

[3] Ganjoo A., Jain H., Yu C., Song R., Ryan J.V., Irudayaraj J., Ding Y.G., Pantano C.G., J. NonCryst. Solids, 352 (2006), 584.

[4] Singh P.K., Dwivedi D.K., Ferroelectrics, 520 (2017), 256.

[5] Al-Agela F.A., Al-Arfajb E.A., Al-Marzoukia F.M., Khan S.A., Al-Ghamdi A.A., Prog. Nat. Sci., 23 (2013), 139.

[6] ZAKery A., Elliott S.R., Optical Nonlinearities in Chalcogenide Glasses and their Applications, Springer, New York, 2007.

[7] Mohamed M., Mater. Res. Bull., 65 (2015), 840.

[8] Khan S.A., Zulfequar M., Hussain M., Physica B, 324 (2002), 266.

[9] El-Korashy A., Bakry A., AbDel-Rahim, M.A., El-Sattar M.A., Physica B, 391 (2007), 266.

[10] FAYEK A.A., El-KAR M., HASSANIEN A.S., Chem. Phys., 70 (2001), 231.

[11] PoPESCU M.A., Non-Crystalline Chalcogenides, Springer Science \& Business Media, 2001.

[12] Boolchand P. (Ed.), Insulating and Semiconducting Glass, World Scientific, New Jersey, 2000.

[13] Cui S., Chahal R., Boussard-Pledel C., NazaBal V., Doualan J.L., Troles J., Lucas J., BuREAU B., Molecules, 18 (2013) 5373.

[14] Sung-Min Y., NAM-YEAL L., SANG-OUK R., KYUJeONG C., PARK Y.S., SEUnG-Yun L., BYOUnGGon Y., Myung-Jin K., Se-Young C., WutTIG M., IEEE Electron. Device. Lett., 27 (2006), 445.

[15] Lu Y., Song S., Shen X., Wu L., Song Z., LiU B., DAI S., NIE Q., ECS Solid State Lett., 2 (2013), 94.

[16] Svoboda R., Kincl M., MaleK J., J Alloy. Compd., 644 (2015), 40.

[17] AbDel-RAhim M.A., AbDel-Latief A.Y., ABDElsalam, Thermochim. Acta, 573 (2013), 57. 
[18] Tripathi S.K., Sharma V., Thakur A., J NonCryst. Solids, 351 (2005), 2468.

[19] Afifi M.A., Hegab N.A., BeKheet A.E., Sharaf E.R., Physica B, 404 (2009), 2172.

[20] Khan S.A., Zulfequar M., Husain M., Physica B, 324 (2002), 336.

[21] Abdinov A.S., Akperov Y.G., Mamdov V.K., SoLAEV E.Y., Sov. Phys. Semicond., 14 (1980), 440.

[22] Kumar H., Mehta N., Glass Phys. Chem., 39 (2013), 490.

[23] Kumar H., Mehta N., J. Adv. Phys., 2 (2013), 163.

[24] RaOuF A.H. El-Mallawany, Tellurite Glasses Handbook: Physical Properties and Data, $2^{\text {nd }}$ ed., CRC Press, London, New York, (2012).

[25] Dwivedi D.K., Pathak H.P., Shukla R.K., KUMAR A., Optik, 126 (2015), 635.

[26] Pathak H.P., Shukla N., Kumar V., Dwivedi D.K., Opt. Mater, 52 (2016), 584.

[27] Bureau B., Hua Zhang X., Smektala F., J. NonCryst. Solids, 345 - 346 (2004), 276.

[28] Padiyan D.P., Mainkani A., Murali K.R., Mater. Chem. Phys., 88 (2004), 250.

[29] Kumar P., Bindra K.S., Suri N., Thngaraj R., J. Phys. D: Appl. Phys., 39 (2006), 642.

[30] SCHERRER P., Nachrichten von der Gesellschaft der Wissenschaften zu Göttingen, MathematischPhysikalische Klasse 2, 1918, p. 98.

[31] Wilson A.J.P., Mathematical Theory of X-ray Powder Diffractometry, Cordon and Breach, New York, 1963.
[32] Al-Ghamdi A.A., Vacuum, 80 (2006), 400.

[33] Al-Agel F.A., Al-ArfaJ E.A., Al-Marzouki F.M., Khan S. A., Al-Ghamdi A.A., Prog. Nat. Sci., 23 (2013), 139.

[34] Khan Z.H., Salah N., Habib S., Al-Ghamdi A.A., KHAN S. A., Opt. Laser Technol., 44 (2012), 6.

[35] TAUC J., Amorp and Liquid Semic., in: TAUC J. (Ed.), Plenum Press, New York, 1979.

[36] Abdel-Rahim M.A., Hafiz M.M., Mahmoud A.Z., Solid State Sci., 48 (2015), 125.

[37] Urbach F., Phys. Rev., 92 (1953), 1324.

[38] Olley J.A., Solid State Commun., 13 (1973), 1437.

[39] Abdel-Rahim M.A., Hafez M.M., Elwhab A., AlWANy B., Opt. Laser Technol., 44 (2012), 1116.

[40] Davis E.A., MotT N.F., Philos. Mag., 22 (1970), 903.

[41] Chaudhri S., Biswas S.K., J. Non-Cryst. Solids, 54 (1983), 179.

[42] Hasegawa S., Kitagawa M., Solid State Commun., 27 (1978), 855.

[43] Nyakotyo H., Sathiaraj T.S., Muchuweni E., Opt. Laser Technol., 92 (2017), 182.

[44] Neet U., Zulfequar M., J. Alloy. Compd., 576 (2013), 103. 